ISSN electrónico: 2172-9077

https://doi.org/10.14201/fjc201715163184

\title{
IMPRONTAS TEATRALES EN EL CINE ARGENTINO CONTEMPORÁNEO: TRES MODALIDADES DE ASIMILACIÓN
}

\section{Theatrical Imprints in Contemporary Argentine Cinema: Three Modalities of Assimilation}

\author{
Dra. Carolina SORIA \\ Profesora Doctora (Jefa de Trabajos Prácticos) de la Universidad de Buenos Aires, Argentina \\ E-mail: soriacarolina@gmail.com \\ (D) orcid.org/0000-0001-5759-3132
}

Fecha de recepción del artículo: 14/07/2017

Fecha de aceptación definitiva: 19/10/2017

\begin{abstract}
RESUMEN
A comienzos del nuevo siglo el cine argentino traslada a su repertorio tópicos y procedimientos narrativos y expresivos provenientes de la práctica escénica de la década anterior. Entre las diversas modalidades de asimilación se distinguen, primero, aquellos films realizados por directores y actores teatrales en los que se evidencian las indagaciones de lenguaje y preocupaciones formales que proceden de su labor escénica. En segundo lugar, se destacan los films de la «puesta en escena» y situaciones mínimas en los cuales hay una revaloración de la imagen por encima de las acciones que se desarrollan en su interior, a través del empleo predominante de recursos estilísticos de clara impronta teatral, como el plano secuencia y la profundidad de campo. Y, por último, sobresalen aquellos films de estructuras episódicas que remiten a la división en actos de las obras teatrales. Dentro de esta categoría reconocemos a su vez dos variantes de dicha estructura: films cuyos episodios son argumentalmente independientes entre sí y films cuyos episodios están conectados por los mismos personajes y por una misma trama.
\end{abstract}

Palabras clave: cine; teatro; intermedialidad; narración; análisis fílmico.

\begin{abstract}
At the beginning of the new century, Argentine cinema added to its repertoire topics, narrative and expressive procedures from the theatre of the previous decade. Among the different modalities of assimilation, we can distinguish in first place the films made by stage directors and actors that evidenced the formal concerns and the inquiries of language that come from their theatrical work. In second place, films of the mise-en-scène and «minimal situations» in which there is a revaluation of the image above the actions that develop in its interior, through the predominant use of stylistic resources of clear theatrical imprint such as the long take and the depth of field. Finally, films with episodic structures that refer to the division into acts of the theatrical works. Within this last category, we recognize two variants of the structure: films whose episodes are arguably independent of each other and those whose episodes are connected by the same characters and by the same plot.
\end{abstract}

Key words: cinema; theater; intermediality; narrative; film analysis. 


\section{INTRODUCCIÓN}

Las relaciones históricas entre el teatro y el cine han sido abordadas en numerosos estudios centrados en seguir los pasos de dicho vínculo desde el origen del cine hasta la actualidad: desde la convivencia con fórmulas de diversa procedencia -como el varieté, el circo y la prestidigitación-, pasando por su institucionalización y constitución como arte autónomo y diferenciado de las otras artes, hasta llegar a una teatralización como forma de reflexión del discurso cinematográfico sobre sí mismo. La subordinación temática inicial del cine hacia al teatro, el acatamiento de sus técnicas y recursos expresivos antes de hallar aquellos de naturaleza exclusivamente fílmica, la utilización de sus elencos actorales y la búsqueda de legitimidad en la adaptación de obras clásicas para atraer a un público elevado sentaron las bases de una relación que, con altas y bajas, perdura hasta nuestros días. Pérez Bowie (2004), al referirse a las relaciones que el teatro y el cine han ido estableciendo a lo largo de la historia, plantea el término de diálogo intermedial para nombrar específicamente a los procesos de interinfluencias bidireccional entre ambos medios, una relación permanente con períodos de mayor o menor fluidez.

Si nos adentramos en el cine argentino contemporáneo, es posible distinguir en él la productividad e intercambio de temáticas, estructuras narrativas y elementos expresivos provenientes del teatro de los noventa, especialmente del teatro de situación realizado por Rafael Spregelburd y definido por él mismo como:

una forma de escribir teatro -o de leerlo- que no privilegia la manera discursiva en la que la literatura o las fábulas dramáticas transmiten contenidos, sino una experiencia en la que una situación, un juego simple de convenciones que dura un tiempo, construye sentidos que entran en colisión con el sentido común de una comunidad que los ve. (Spregelburd, 2005, p. 282).

Mi objetivo es postular que las características de este teatro, a la vez que mantienen un estrecho vínculo con el teatro posdramático (Hans-Thies Lehmann, 2010), contienen en germen aquello que sucede en el cine argentino a comienzos del nuevo siglo y que propuse denominar cine de situación ${ }^{1}$ al trazar un conjunto de regularidades que comparten ambas manifestaciones culturales (Soria, 2015b). Las características del teatro posdramático describen y permiten reflexionar sobre la práctica escénica de los noventa a la vez que autorizan su extrapolación al ámbito cinematográfico y la referencia a un cine posdramático. Lehmann define a dicho teatro como un teatro antiaristotélico que se resiste a expresar un sentido unívoco relacionado con un referente previo y que, por el contrario, busca restituir la materialidad del lenguaje propiamente escénico y desterrar a la trama a un lugar subsidiario. La noción de representación en su sentido de imitación de la vida es sustituida por la de presentación, ya que este teatro «borra las fronteras entre lo real y lo ficcional, y, por supuesto, no se postula como doble o espejo, sino como equivalente de la vida misma» (Lehmann, 2012, s/p). En este teatro los diálogos dejan de ser realistas, las acciones se caracterizan por la indefinición y los personajes no se constituyen como seres reconocibles con un delineamiento psicológico. Por otro lado, y con respecto a la posibilidad de pensar en un teatro posdramático en la Argentina, Karina Mauro (2013) analiza la

\footnotetext{
${ }^{1}$ Con la noción de cine de situación me refiero, en primera instancia, a un cuerpo textual fílmico en el que se privilegia una construcción discursiva centrada en la composición de los elementos profílmicos. En una segunda instancia, sugiero el énfasis en la puesta en escena a partir de elementos expresivos tales como el plano secuencia, la profundidad de campo y la inmovilidad de la cámara, cuya articulación no obedece tanto a las leyes de una lógica narrativa, sino simplemente a la de una sucesión de situaciones, destinadas principalmente a la mostración del discurrir temporal y afectivo de un grupo de personajes.
}

Ediciones Universidad de Salamanca / CC BY - NC ND $\quad$ Fonseca, Journal of Communication, n. 15, 2017, pp. 163-184 
productividad del concepto en la escena teatral porteña a partir de los noventa. La investigadora examina dicho teatro como práctica directorial, en tanto la responsabilidad del enunciado escénico atañe a la figura del director, subrayada a partir del evidenciamiento de las marcas de enunciación que estaban completamente borradas en el drama moderno. Este artículo es crucial porque, si bien corrobora el rendimiento del concepto al abordar el corpus fílmico que presento a continuación, permite extrapolarlo al ámbito de la estética cinematográfica y postular la posibilidad de existencia de un cine posdramático. En líneas generales, Mauro sostiene que «aquello de lo que la escena posdramática es el resultado o el fiel testimonio, es de la crisis de la representación y, en términos teatrales, del abandono de la mímesis aristotélica» (2013, p. 672). A su vez, la investigadora define dos aspectos generales de las obras posdramáticas que son fundamentales a la hora de analizar los films, como «el carácter problemático del texto dramático y el tratamiento fragmentario de los componentes que otrora constituían las unidades aristotélicas» (p. 675). Es decir que el teatro posdramático -y su equivalente cinematográfico- descompone la tríada de lugar, acción y tiempo postulando espacios fragmentarios, acciones desprovistas de una motivación racional y una temporalidad basada en la puesta en ritmo (Mauro, 2013), consistente en «la reiteración de momentos o comportamientos no significativos en sí mismos, pero que, mediante su repetición constante o acelerada, resulta en una escansión determinada de la escena» (p. 676). Este procedimiento es nodal y se repite sistemáticamente tanto en las textualidades fílmicas que escogimos.

Procuro entonces establecer y delinear los tres modos en que el teatro ha sido asimilado por el cine del nuevo siglo, una asimilación que se asemeja a la reformulación de la «teoría de las ondas» que propone Bill Nichols (2007). Esta teoría permite comprender «cómo ciertos elementos estilísticos o estructurales pueden mantenerse vigentes a lo largo del tiempo y producir resultados complejos, sincréticos o híbridos» (Nichols, 2007, p. 20). Partiendo de esta idea, me interesa reconocer los rasgos comunes que comparten ambos lenguajes, porque los veremos diseminados a lo largo del corpus que organicé en función de características similares y de las diversas formas de apropiación:

1) particular concepción de la comunicación (desintegración de lenguaje y pérdida de la función referencial, autorreferencialidad), 2) fragmentación y narraciones episódicas, ausencia de la causalidad lógica, privilegio de la imagen y de la experiencia por sobre el relato, tramas inverosímiles, 3) desdoblamiento y disolución de los personajes, motivaciones opacas, 4) multiplicación de sentidos. (Soria, 2015b, p. 45).

Estas «reglas cardinales» comunes a la práctica escénica y al cine se articulan de manera integral (tanto a nivel formal como narrativo) con las siguientes modalidades de asimilación ${ }^{2}$ que postulo:

1) Films realizados por directores y actores teatrales en los que se evidencian las indagaciones de lenguaje y preocupaciones formales que provienen de su labor escénica -Todo juntos (2002, Federico León), Extraño (2003) y Cuatro mujeres descalzas (2004, Santiago Loza)-.

\footnotetext{
${ }^{2}$ Si bien mi objetivo en esta oportunidad es analizar la asimilación del teatro por parte del cine, es posible reconocer una inversión de influencias que atañen a procedimientos cinematográficos en la práctica escénica contemporánea. Por ejemplo y siguiendo con los directores a los que aludimos en este artículo, Federico León y Rafael Spregelburd, en sus puestas teatrales hay un consciente y deliberado empleo de recursos audiovisuales, como la proyección de grabaciones y la manipulación del tiempo y el espacio. Algunos ejemplos son las obras que integran la Heptalogía de Hieronymus Bosch, especialmente La paranoia (2007) de Spregelburd y Yo en el futuro (2009) de León.
}

Ediciones Universidad de Salamanca / CC BY - NC ND $\quad$ Fonseca, Journal of Communication, n. 15, 2017, pp. 163-184 
2) Films de la «puesta en escena» y situaciones mínimas en los cuales la revaloración de la imagen por encima de las acciones que se desarrollan en su interior relega a estas a un segundo plano -Sábado (2001, Juan Villegas), Incómodos (2008, Esteban Menis), Ocio (2010, Alejandro Lingenti y Juan Villegas)-.

3) Films de estructuras episódicas que remiten a la división en actos de las obras teatrales. Dentro de esta categoría reconocemos a su vez dos variantes de la estructura episódica: a) films cuyos episodios son argumentalmente independientes entre sí - A propósito de Buenos Aires (2006, AA. VV.), Luego (2008, Carola Gliksberg), Vidrios (2013, Ignacio Bollini y Federico Luis Tachella)-; b) films cuyos episodios están conectados por los mismos personajes y por una misma trama -Castro (2009, Alejo Moguillansky), Todos mienten (2009, Matías Piñeiro), El turno nocturno (2011, Matías Rispau)-.

En cada una de ellas se integran entonces y de manera diversa los procedimientos provenientes del teatro con aquellos de naturaleza fílmica y de dicha interacción es posible extraer patrones comunes, cuya organización en las modalidades trazadas contribuye a delinear una de las formas de manifestación del cine argentino contemporáneo. Los films que componen dichas modalidades pueden a su vez vincularse con la noción de cine anómalo planteada por Gonzalo Aguilar, un cine que no necesariamente se enfrenta a un orden establecido, sino que se realiza al margen de él, crea nuevos circuitos de exhibición y reubica al cine en el mundo del arte estableciendo conexiones y líneas de fuga (Aguilar, 2010, p. 241).

A continuación, propongo esbozar los rasgos de cada uno de estos films en función de los elementos que permiten analizarlos en términos de cine de situación o cine posdramático y que son portadores de dicha impronta teatral. Pondré especial énfasis en examinar los procedimientos narrativos y expresivos, la construcción temporal y espacial, el sistema de personajes y la poética actoral de los films en función de establecer, tanto las características que comparten, como las singularidades específicas que permiten adscribirlos dentro de cada modalidad.

1) Films REALIZADOS POR DiRECTORES TEATRALES. En esta primera modalidad incluyo aquellos films realizados por dramaturgos y directores en los que se evidencian huellas de su proceder escénico.

\section{TODOJUNTOS}

Este film está concebido desde un primer momento para ser llevado a cabo con procedimientos provenientes del teatro. Así lo expresa Federico León en Registros..., en donde reflexiona acerca de sus intenciones de hacer una película a partir de convenciones teatrales, desde el proceso de construcción hasta el empleo de los espacios, los personajes y la actuación. El tema que atraviesa Todo juntos es el estadio final de una pareja en pleno proceso de separación que no logra poner fin a su relación. Federico León y Jimena Anganuzzi son prácticamente los únicos personajes del film y merodean por diferentes espacios públicos como bares, cabinas de locutorios y taxis. Como señala el director: «Uno no puede averiguar cuál es el conflicto, por qué se están separando. La película está empezada en todo sentido. Eso es similar a mis obras de teatro: el relato es la relación entre personajes en un lapso de tiempo y el devenir de esos personajes» (en García, 2003). No sabemos entonces cuál es la razón de la separación, ni tampoco por qué les cuesta tanto hacerlo, simplemente somos espectadores de un ir y venir constante de la pareja que, hacia el final de la película, permanece de forma idéntica que al comienzo, tomando café y en una actitud impasible. El empleo de convenciones teatrales y la ficción 
propuesta en Todo juntos se complementa con el aspecto autobiográfico de la historia: Federico León y Jimena Anganuzzi eran pareja fuera de la ficción y, al igual que en el film, estaban atravesando la separación. Es decir, que el film, además de poner en escena la vida personal del director, muestra a su vez su proceso de construcción develando la relación director-actriz:

Como en todas las obras, me interesa que la misma obra dé cuenta de cómo fue hecha. También podía decir que la película era la relación entre un director y una actriz. Le pedía que hiciera determinadas acciones, como si ella fuera la más expuesta y yo le daba órdenes. Así fue el proceso. La cámara filmaba y yo mismo actuando le pedía a ella que hiciera cosas. O sea que la dirigía estando adentro mismo de la película, como si ésa fuese la dinámica de relación de esa pareja (en Fontana, 2005, p. 11).

Retóricamente el film comienza con una escena en el campo en la que Federico León carnea un cerdo. La calidad de la imagen sugiere que se trata de un video casero y esto se confirma cuando la imagen se congela y aparece enmarcada por un televisor. Inmediatamente se escucha sonar el teléfono y así comienzan las idas y venidas de los encuentros y desencuentros entre Federico y Jimena, siempre interrumpidos por llamados telefónicos de familiares y amigos. La recurrencia de primeros planos de extensa duración con los rostros de los protagonistas, su mirada perdida y dirigida hacia el fuera de campo y los silencios que invaden la imagen crean un clima opresivo y de creciente incomodidad. Los encuentros y las llamadas permanentes logran, paradójicamente, la total incomunicación y el desacuerdo. Sumado a la composiciòn de los planos y en relación con la noción de cine de situación, Todo juntos está conformada por una sucesión de situaciones que atraviesan los personajes y que los muestra siempre de la misma manera, indecisos y agotados por un estado de incertidumbre irresuelto, convirtiendo al film en una narración circular. El director define su ópera prima cinematográfica de la siguiente manera: «Todo juntos es la historia de un estado. De un devenir de los personajes por el mundo de lo acabado» (en Blejman, 2003), es decir, un estado único que permanece inmutable pero que resulta cada vez más tedioso por el paso inexorable del tiempo.

El director, además de emplear el mismo proceso creativo tanto en sus obras teatrales como en su ópera prima -y similares procedimientos expresivos y narrativos-, reconoce en los últimos años la estrecha relación y el acercamiento del cine al teatro independiente,

El cine independiente empezó a ver cómo producía el teatro y le «robó», digamos, formas de producción al teatro independiente, las asimiló para el cine. Y también formas de exhibición. (...) El teatro siempre admiró al cine, pero el cine le tenía un poco de fobia al teatro. Algunos directores de cine le tenían un poco de miedo a esa situación de estar ahí con los actores en vivo. Hará unos 10 años que empezó a acercarse el cine al teatro. Fue muy bueno este encuentro; se nutrieron los dos (en Maxwell, 2013).

Esta presencia del teatro en el cine y el lazo entre ambos también es expresada por Gonzalo Aguilar (2007) en relación con el film de León de la siguiente manera: «La poesía (la antipoesía si se prefiere, que es el modo contemporáneo de la poesía) es el puente entre el cine y el teatro, el puente que es a la vez un hiato o un hueco» (Aguilar, 2007, p. 20). Una poesía que, según el investigador, emana del descubrimiento por parte del cine de aquellos lugares de tránsito como los bares o el locutorio en 
donde circula el lenguaje, «un lenguaje profundamente poético si por poesía entendemos un ritmo encantatorio que ha perdido sus motivos líricos» (p. 20). Se trata, en definitiva, de un reconocimiento rotundo por parte del realizador, como también de investigadores especializados, de la relación entre ambas manifestaciones artísticas. Los procedimientos utilizados y las operaciones combinatorias de los mismos convierten a Todo juntos en un ejemplo paradigmático de esta primera variante.

\section{EXTRAÑ}

Este film es la ópera prima de Santiago Loza, dramaturgo y director con una cuantiosa producción teatral en su haber al momento de su estreno.

Axel, protagonista de Extraño e interpretado por Julio Chávez, es un médico cirujano retirado del ejercicio. Se trata de un hombre de pocas palabras y distante cuyo desenvolvimiento a lo largo del film y su personalidad son impenetrables. Desde el inicio se lo ve impávido e indiferente a lo que le rodea, responde sin emitir sonido a través de gestos corporales y faciales (levantando los hombros, las manos y las cejas, ladeando la cabeza hacia un costado o esbozando apenas la mueca de una sonrisa). Si atina a responder algo verbalmente, lo hace con monosílabos cortantes y definitivos: «Sí, claro». Al comienzo del film, Axel entrega las llaves de su departamento y se va a vivir temporalmente con su hermana y sus sobrinos. En esta secuencia inicial accedemos a la escasa información que nos brinda la película sobre su protagonista: es un médico cirujano (joven) que no ejerce más su profesión -desconocemos el motivo- y tampoco le interesa reinsertarse en el ámbito laboral. También desde el inicio se establece el modo en que el relato lo retratará a lo largo del film: con una cámara fija sobre el protagonista y unos muy pocos contraplanos de sus interlocutores. En la mayoría de las sucesivas secuencias prevalecen la inmovilidad, la escasa variación de puntos de vista dentro del plano y el empleo de interiores. Mediante esos recursos, el universo que crea el film está poblado de seres solitarios que llevan adelante su vida de un modo impasible. Axel, más que hablar, escucha a aquellos que le rodean: a su hermana separada y a cargo de dos chicos; a Erica, una mujer embarazada con quien convive desde hace muy poco, y a la madre de su amiga, quien se suicidó y a quien le entrega una caja con sus pertenencias. Estos acontecimientos que presuponen cierta trascendencia y dramatismo (abandonar una profesión, ser madre soltera o atravesar el suicidio de una amiga) por el contrario no tienen ni reclaman explicación alguna y están despojados de toda emoción.

$\mathrm{Al}$ adentramos en el reconocimiento de una impronta autoral y en la identificación de las huellas de la dramaturgia de Loza, es posible identificar en Extraño la construcción de personajes que manifiestan rasgos similares con aquellos que pueblan sus ficciones previas. Una voz en off que exterioriza el pensamiento de Axel explicita su retraimiento frente al entorno: «Hay un tiempo que no me pertenece, ni adelante ni atrás. Un tiempo al que nunca llego». Este sentimiento del protagonista es compartido por otros tantos personajes que conforman la poética dramática de Loza, a quienes Jorge Dubatti describe de la siguiente manera: «Los personajes parecen encerrados en su mundo, en un universo minimalista de percepciones fragmentarias, cotidianas (...) Son tan reflexivos como inactivos, testigos de un mundo ajeno en el que no acaban de encontrar su lugar» (Loza, 2014, p. 10). Sin embargo, es preciso mencionar una diferencia abismal con respecto a su teatro: así como el protagonista de Extraño y las protagonistas de Cuatro mujeres descalzas -y podemos incluir también a los protagonistas de La invención de la carne (2009)- prácticamente no emiten discurso y son pura presencia y corporalidad, sus personajes teatrales ${ }^{3}$ no hacen otra cosa que hablar. Andrés Gallina en el «Estudio preliminar» de

\footnotetext{
${ }^{3}$ Nos referimos a los personajes de los monólogos de Todo verde, La mujer puerca y Asco, entre otros.
} 
Textos reunidos, sostiene que el teatro de Loza es un «teatro de voces» y que sus personajes buscan «traducir y afirmar la experiencia» (Loza, 2014, p. 17). En cambio, en los films, los personajes transitan la experiencia sin necesidad de reflexionar ni postular nada sobre ella, subrayando la posibilidad de que el relato lo arme el cuerpo del actor con sus gestos y silencios sin tener la necesidad de recurrir a la palabra.

Como contrapunto de las escenas interiores del film, se insertan entre ellas a modo de transición imágenes fijas -como si de naturalezas muertas se trataran- o travellings de diferentes enclaves de la ciudad, todos ellos lugares ignotos que refuerzan la ausencia de cualquier tipo de referencialidad, intensificando a su vez el sentimiento de enajenación del protagonista. Estas imágenes son planos vacíos de la ciudad y de la naturaleza que expresan, a su vez, el paso del tiempo y la espera.

Santiago Loza confiesa en una entrevista su interés por la sombra -zona intermedia entre el cuerpo y el fondo- y las temporalidades, por ese tiempo «entre» un antes y un después, «viajes intermedios que no tienen un punto de partida ni de llegada» (p. 39). Ese intersticio es la forma oculta que subyace a nuestro corpus y que consiste, a nivel visual, en mostrar el despojo, en desnudar el espacio, no tanto para resaltar o darle mayor relevancia a la figura, sino para dar cuenta de aquello que escapa a lo visible, que no podemos asir con la mirada, pero que indudablemente toma forma en esos resquicios como una sombra. A nivel del lenguaje prevalece una tensión entre lo dicho y no dicho o más precisamente, aquello que el lenguaje no puede nombrar. Justamente y en alusión a Extraño Loza precisa que «los personajes no pueden definir el núcleo del dolor, van detrás de algo que no encuentran la manera de cómo asirlo» (en Jacobs, 2007, p. 39).

\section{CUATRO MUJERES DESCALZAS}

Este film, del mismo director, significa el debut cinematográfico de la actriz María Onetto, quien a partir de esta primera incursión en el cine no dejará de transitar los dos medios expresivos. Los personajes aquí son cuatro mujeres: Verónica, Bárbara, Marta y Sandra. Todas ellas tienen en común la soledad, la tristeza, el vacío y el miedo, están desempleadas y apenas tienen ganas de reír. Durante el transcurso de Cuatro mujeres descalzas se construyen los vínculos que establecen las protagonistas y de forma gradual pero sesgada accedemos a las vidas de cada una de ellas: Verónica está dejando su departamento porque no puede pagar el alquiler y debe volver a la casa de sus padres. Sus días transcurren en un espacio interior, entre cajas ya embaladas y unas cortinas de plástico que velan su imagen. Su único contacto con el exterior es un teléfono y su amiga Bárbara, quien tiene problemas económicos y decide alquilar una habitación vacía de su casa a Sandra, una mujer casada y embarazada que no sabe si traer un hijo «a un mundo que no podría explicarle». Marta, por su parte, es amiga de Bárbara y llega a Buenos Aires desde el interior en busca de un trabajo.

El tema de la tristeza atraviesa el film, desde el lenguaje corporal y gestual de los personajes hasta los diálogos que mantienen: «¿Parezco alegre o triste?» pregunta Bárbara a cada una de ellas, «Yo cuando estoy contenta me empiezo a preocupar porque me pregunto si no me estaré volviendo loca», dice Bárbara. La pregunta por el «parecer» indica una actitud condicionada o bien preocupada por la mirada del otro y transmite la necesidad de los personajes de salir de ese aspecto introspectivo y claustrofóbico que los caracteriza ${ }^{4}$. Estos diálogos, que apuntan a exteriorizar los sentimientos y emociones y manifestar la necesidad de su expresión, por momentos se presentan enigmáticos, sin una lógica

\footnotetext{
${ }^{4}$ Esta inquietud y necesidad de la mirada ajena se reitera en un film posterior del director. En La invención de la carne de la aparente apatía e indiferencia de los personajes emerge la siguiente conversación: «Él: ¿Qué pensarán de nosotros? ¿Qué imaginará la gente que nos está mirando?; Ella: ¿'Te importa?; Él: ¿Qué?; Ella: Lo que piensen; Él: No sé».
}

Ediciones Universidad de Salamanca / CC BY - NC ND $\quad$ Fonseca, Journal of Communication, n. 15, 2017, pp. 163-184 
entre pregunta y respuesta, hecho que subraya la dificultad de su comprensión por parte de las protagonistas.

En la búsqueda de entender el sentido de la propia existencia estas cuatro mujeres se mueven en espacios oscuros, cerrados y despojados; y el silencio que acompaña su «estar en el mundo» es irrumpido principalmente con reflexiones en torno a los miedos, las tristezas y los desamores de cada una de ellas. La artificiosidad de los diálogos, sumada a la representación de los espacios, le imprimen al film una absoluta impronta teatral, reforzada a nivel formal a través del predominio casi absoluto de la cámara fija, con planos secuencia en interiores y ausencia de planos de referencia. Como contrapunto y diseminadas a lo largo de Cuatro mujeres descalzas, se emplean escuetas imágenes fragmentadas de rostros, cuerpos y espacios a través de primeros planos y planos detalles. El movimiento fílmico, al igual que sucedía en Extraño, surge generalmente de travellings horizontales de las calles de la ciudad o de autopistas que marcan la transición entre una escena y otra.

En relación con la temporalidad que propone el film, este oscila entre dos procedimientos comunes de nuestro corpus: por un lado, nos encontramos con una coincidencia plena entre el tiempo de la historia y el tiempo del relato, mediante el uso de los largos planos-secuencia que recién mencionamos; por otro, asistimos a un relato absolutamente fragmentado en el que la elipsis es el recurso predominante en la unión de los planos. En el primer caso, la temporalidad de la acción desarrollada en el film coincide con la de la realidad significada, «sin ninguna presencia de alteraciones dinámicas, de elipsis o de particulares transformaciones rítmicas debidas a intervenciones de montaje». (Bettetini, 1984, p. 37). Señala Bettetini que «nos hallamos ante una auténtica reproducción, un auténtico registro pasivo del tiempo real que puede ser recuperado en su totalidad y en sus articulaciones con cada proyección de la película sobre la pantalla» (p. 38). En el segundo caso, por el contrario, los tiempos de la acción difieren del tiempo de la realidad representada por la presencia de alteraciones dinámicas, de figuras elípticas o de «transformaciones rítmicas causadas por intervenciones de montaje» (p. 38). La combinación de dos temporalidades es recurrente en el corpus fílmico que examinamos en este artículo, sobre el cual me interesa destacar que, si bien prevalecen procedimientos que remiten a la escena teatral como el plano secuencia y la profundidad de campo, estos interactúan con la naturaleza fragmentaria del propio dispositivo cinematográfico y su capacidad de subrayar la relevancia de determinados detalles. Son las diferentes modalidades de interacción entre los procedimientos escriturales esenciales de cada práctica artístistica lo que me interesa delinear en este recorrido a través de las textualidades fílmicas que lo componen. Según Jaques Aumont (2013) en El cine y la puesta en escena, el découpage es la representación de la diferencia entre el cine y el teatro y es donde se consuma la invención de la forma fílmica. Sin él, «la puesta en escena del cine estaría condenada a ser por siempre el calco de la puesta en escena teatral» (2013, p. 48).

Esta primera modalidad corrobora la eficacia del concepto de cine posdramático y atestigua la resonancia de su antecedente teatral, en tanto es portadora de sus características principales como la disgresión e indeterminación narrativa, la ausencia de explicaciones y motivaciones opacas y la restitución de la materialidad del lenguaje.

Más allá de las singularidades estéticas de estos dramaturgos, ellos comparten una propuesta similar en lo referido a la actuación en sus puestas en escena. Creemos que la disposición actoral construida escénicamente migra de la mano de los mismos actores hacia el cine. Sin embargo, más allá de percibir en él una poética actoral similar, creemos pertinente considerar la noción de situación de actuación formulada por Karina Mauro (2015), quien la entiende como el «contexto espacio-temporal en el que el sujeto acciona actoralmente». Esto quiere decir que la situación de actuación se modifica 
según los diferentes lenguajes estéticos ${ }^{5}$ y se diferencia, según la investigadora, de la acción cotidiana en la medida en que se produce para la mirada de otros. Las características que extraemos de la situación de actuación del corpus en sus diferentes modalidades son principalmente la no representación, la presentación de acciones por parte del actor que se modifican según los elementos de la puesta en escena y del contacto con los otros actores, es decir, la permeabilidad ante todo aquello que acontece durante la situación de actuación, la distancia respecto del personaje y la fluctuación permanente entre la conciencia y la inconciencia de estar actuando. En el caso de Extraño y Cuatro mujeres descalzas, si bien los actores llevan adelante acciones en nombre de los personajes que interpretan y estos presentan atributos mínimos de caracterización, hay una distancia infranqueable entre actor-personaje en la medida en que se muestra de manera sistemática el artificio de la situación de actuación cinematográfica: por el modo en que son registrados por la cámara, por la relación con los demás personajes y por los diálogos. Distancia que se traslada también al proceso identificatorio del espectador, para quien resulta imposible entablar o llegar a sentir empatía con el personaje. En Todo juntos se apela al mismo proceso de construcción actoral que en la práctica escena. La particularidad o excepcionalidad de este film reside en su cualidad de obra autobigráfica que implica nuevamente una tensión entre lo ficcional y lo real y, a la vez, una identificación plena entre actor-personaje. La relación de pareja en su estadio final de los protagonistas se corresponde con una situación similar en la vida del director Federico León y la actriz Jimena Anganuzzi, por lo que se produce un doble vínculo en la relación de la acción actoral: relación amorosa en su fase terminal, tanto en la vida real como ficcional o situación de actuación; relación director-actriz en la situación real (León dirige a Anganuzzi en el film al mismo tiempo que actúa).

\section{2) FILMS DE LA «PUESTA EN ESCENA» Y SITUACIONES MÍNIMAS.}

En esta variante cobra preeminencia la puesta en escena a partir de la relevancia otorgada al desplazamiento de los actores y a la disposición dentro del cuadro de los elementos profílmicos. La historia ocupa un lugar secundario y las situaciones que atraviesan los personajes son mínimas. El acento en la puesta en escena se relaciona con el retorno de la imagen que menciona Aumont (2013) a propósito del cine de autor. Según el teórico, el regreso del gusto por la imagen coincide también con el retorno de «una teatralidad aparente que debe revelarse muy cinematográficamente» (p. 113). En los films que constituyen esta modalidad veremos que predominan los tiempos muertos y la ausencia de climax narrativos, y es en ellos donde podemos encontrar la expresión más cabal de lo que denomino cine de situación.

\section{SÁBADO}

La historia de la ópera prima de Juan Villegas se centra en el discurrir del día sábado en la vida de tres parejas. Comenzada in medias res, la escena inicial nos sitúa en el interior de un auto donde una pareja conversa displicentemente. A continuación, se hilvanan sin solución de continuidad y de manera simultánea, las historias de las tres parejas que se entrecruzan a lo largo del film de manera fortuita (en la comisaría, en la peluquería, en la calle). Los momentos que suponen mayor conflicto son eludidos: los reiterados choques de autos son tomados con calma y total naturalidad; o tener relaciones

\footnotetext{
${ }^{5}$ Una relación directa entre actor-espectador en el caso de la práctica teatral; una relación mediada por el dispositivo fílmico en el caso del cine.
} 
sexuales con el novio de una amiga tampoco supone un problema. Sábado está constituido por una sucesión de situaciones nimias que no conllevan el desarrollo narrativo clásico de presentacióndesarrollo-desenlace, sino que, por el contrario, responden a un encadenamiento regido por la arbitrariedad de los encuentros y los diálogos. Sobre el énfasis de la puesta en escena en este tipo de films Rafael Filipelli (2001) expresa, en El Amante, que Villegas resalta su importancia narrativa manteniendo la unidad formal y de representación del espacio cinematográfico, logrado a partir del montaje por corte dentro de la escena. Según el director y crítico de cine, es justamente en las escenas interiores donde se logra la mayor movilidad dentro del cuadro gracias a los reencuadres permanentes.

La omisión de escenas como los accidentes y las escenas de sexo que mencioné más arriba es justificada por su director al señalar que en la película se trata justamente de «no poner énfasis en nada» (Bernini, et al., 2003, p. 161). Villegas, al recordar cómo fue el proceso de construcción del film, confiesa que al principio no tenía una historia, sino situaciones cotidianas a las que articuló manteniendo una marca temporal: el transcurso de un día. En relación con la construcción de los personajes, admite: «no tenía sentido trabajar sobre lo psicológico de las situaciones, a pesar de que a veces los actores suelen reclamar algo en ese sentido. Yo prefería trabajar, no lo psicológico, sino sobre el ritmo, la velocidad, las pausas» (Bernini, 2003, p. 158). Por último, el cineasta manifiesta que sus películas hablan de lo que les pasa a los personajes, o, mejor dicho, de personajes que no dicen lo que les pasa, porque según el director «a ellos les pasan muchas cosas, (...), son personajes que sufren» (Bernini, et al., 2003, p. 157).

Las conversaciones que mantienen los personajes son completamente triviales y repetitivas. Como veremos en este film, como también en aquellos pertenecientes a otras modalidades, se radicaliza la utilización del habla cotidiana, con un lenguaje despojado de su entonación habitual, con repetidos y cifrados y completamente uniforme. En los diálogos de Sábado, por ejemplo, los personajes hablan mucho sin decir nada, de cosas triviales e insignificantes. Agustín Campero señala que, al igual que Rejtman, «Villegas comparte la obsesión por los diálogos, por su métrica, su tempo y el despojo de los tonos innecesarios. E instaura una dictadura de la puesta en escena y la unidad formal» (2008, p. 67). En la escena inicial del film, cuando Camila y Leopoldo están en el auto, la conversación repetitiva se torna exasperante:

$$
\begin{aligned}
& \text { Leopoldo (mientras conduce): ¿Es por acá? } \\
& \text { Camila (en el asiento del acompañante): No } \\
& \text { L: ¿No? } \\
& \text { C: Sí, es por acá } \\
& \text { L: ¿Sí o no? } \\
& \text { C: ¿Sí o no qué? } \\
& \text { L: ¿Es por acá o no? } \\
& \text { C: No, vos seguí } \\
& \text { L: ¿Pero cuánto falta? } \\
& \text { C: ¿Para qué? } \\
& \text { L: Para llegar } \\
& \text { C: No sé } \\
& \text { L: ¿Te perdiste? } \\
& \text { C: No } \\
& \text { L: ¿Segura? } \\
& \text { C: Sí } \\
& \text { L: ¿Querés la Lumi? } \\
& \text { C: No } \\
& \text { L: Está ahí atrás }
\end{aligned}
$$




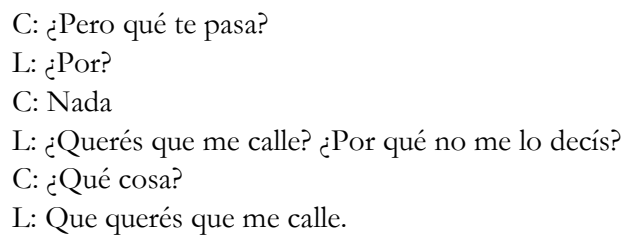

En el film se percibe la no representación en su forma extrema con Gastón Pauls haciendo de sí mismo y corrigiendo la pronunciación de su apellido. En este caso se produce una tensión entre ficción y realidad en la que el actor real interpreta una versión de sí mismo en un universo ficcional.

\section{INCÓMODOS}

Nicolás, Abril y Alfred viajan a Miramar en pleno invierno y por diferentes motivos. El de Nicolás, es esparcir las cenizas de su abuelo difunto, el de Abril, reencontrarse con su familia y el de Alfred, participar en un concurso de baile. La presentación de cada uno de ellos acontece previamente a los créditos iniciales, en donde los vemos enfrentar diferentes situaciones de abandono: a Nicolás lo ha dejado su novia Paula, a Alfred lo expulsa el grupo de baile con el que esperaba presentarse al concurso y Abril, personaje tímido y solitario, no ve a su familia desde hace años. Tras los créditos, comienza una road movie que toma como escenario la ciudad de Miramar fuera de temporada, localidad costera en la que cada uno de los protagonistas busca dar sentido a la travesía emprendida.

A nivel visual, Incómodos se construye a través de planos fijos y centrados, la mayor parte de ellos compuestos de manera simétrica. Hay un completo develamiento del artificio cinematográfico al asumir la cámara el punto de vista del espectador, especialmente en aquellas escenas en donde los personajes dirigen su mirada y parlamentos hacia ella. A su vez en estas escenas hay una marcada huella teatral en la medida en que el plano comienza fijo y vacío, el personaje ingresa por un lateral hasta situarse en el centro de la porción visual, emite su discurso de manera frontal al dispositivo y vuelve a salir del cuadro. El centrado y la simetría son los emplazamientos de cámara más utilizados por Esteban Menis en este film, ya sea para la descripción de los espacios interiores y exteriores, como para la ubicación de los actores dentro del plano. Asimismo, hay un deliberado empleo de los colores primarios (azul, rojo y amarillo) en los vestuarios de los personajes, colores que resultan llamativos en tanto contrastan sugerentemente con su estado de ánimo apagado y de incomodidad y con los grises y los colores pálidos que caracterizan a una ciudad balnearia invernal y fuera de temporada.

Con respecto a los diálogos, en Incómodos, el lenguaje es verborrágico, automático y compulsivo, negando por momentos toda posibilidad de interlocución. La noche en que se conocen Nicolás y Abril, ella se presenta de un modo que roza el reporte periodístico:

Mi tarea es dirigir las operaciones de las estaciones de peaje y asegurar la recepción de la tarifa vigente de manera rápida, eficiente y con la menor interferencia posible del tránsito vehicular. Desde la puesta en marcha de la autopista en 1994, la cantidad de automovilistas que ha elegido esta modalidad de pago va en constante aumento. En la actualidad superan los 110.000 clientes y seguimos creciendo. 
Esta forma de parlamento está presente a lo largo de todo el film, como si el objetivo fuese mostrar la automatización y artificialidad de las palabras que impiden cualquier tipo de comunicación y entendimiento entre los personajes. Por último, y al igual de lo que le secedía Axel en Extraño, Alfredo expresa: «siempre tengo esa sensación de que estoy afuera de todo lo que pasa».

Los protagonistas están unidos por un vínculo desconocido que nunca se termina de explicitar; tienen en común la soledad, la infelicidad y un viaje a Miramar -fuera de temporada- durante el cual transcurre la mayor parte del film. Como el título indica, todo en el film resulta incómodo y extraño: desde las conversaciones triviales a las más profundas relacionadas con la felicidad. Los personajes, sin embargo, son conscientes de su pesar, pero no pueden ni tienen intención de hacer algo al respecto. Llama la atención la tardía reacción de los personajes ante los estímulos externos. Hay una especie de dilación en las conversaciones en donde la réplica al parlamento del interlocutor se demora unos segundos, anulando cualquier tipo de fluidez en los diálogos y reforzando el retraimiento de los personajes. Se trata, en la mayoría de los casos, tal como lo plantea Gonzalo Aguilar en Otros Mundos, «de personajes amnésicos, verdaderos zombies, que no vienen de ningún lugar ni se dirigen a ningún otro, obsesionados por un mapa indescifrable» (Aguilar, 2006, p. 30).

El desarraigo que ostentan la mayoría de nuestros personajes fílmicos encuentra su forma en el viaje como disparador de las historias. Y el viaje constituye uno de los rasgos característicos planteados por Zygmunt Bauman (2002) al analizar la época contemporánea, en tanto ya no existen lugares fijos y predeterminados en los cuales «rearraigarnos» y, si los hay, se presentan frágiles y se desvanecen antes de cualquier intento.

\section{OCIO}

Basado en el libro homónimo de Fabián Casas, Ocio se centra en los días posteriores de Andrés (Nahuel Viale) tras haber enterrado a su madre. Tal como el título del film de Lingenti y Villegas lo expresa, la historia transcurre en la cotidianeidad del protagonista en la que tienen lugar situaciones de completa inactividad: estar acostado en la cama y mirar al techo, escuchar música o leer a Camus, observar cómo se consume la llama de un fósforo mientras el agua se calienta para preparar un té, ir a una fiesta, comer en silencio con su hermano y su padre, pasar el tiempo con un amigo y fumar marihuana. La desidia del personaje en este caso en particular está justificada por el proceso de duelo que atraviesa, un duelo por la pérdida de la madre, pero también por una etapa que concluye: la adolescencia. No hay una progresión dramática, sino más bien un devenir de esas situaciones que configuran la línea argumental. Recién hacia el final del filme un momento de tensión se presenta atentando la integridad física de Andrés: una banda motoquera lo aguarda en la puerta de su casa para darle una golpiza con motivo de una deuda que asumió por una moto que compró. Como ocurría en Sábado, esta escena que supone un conflicto o amenaza hacia el protagonista, no es representada como tal y pasa a constituir, anecdóticamente, un momento más en la pasiva vida de Andrés.

Retóricamente, el film se edifica a través de primeros planos -principalmente en los interiores- y planos generales en los exteriores, como aquel del inicio de un camino vacío y de larga duración, cuya sinuosidad permite ver, luego de algunos segundos, a tres hombres (Andrés, su hermano y su padre) que se acercan caminando lentamente. Inmediatamente, tres primeros planos sucesivos de cada uno de sus rostros los individualizan y el último (de conjunto y clausura de esta secuencia inicial) los visualiza frente al nicho del cementerio en donde han enterrado a la madre. A partir de este momento de pérdida de la figura materna, la familia comienza a desintegrarse, viviendo cada uno el duelo en soledad y sin exteriorizarlo ni dialogarlo entre sí. 
Me interesa hacer referencia, en este punto, a que este film representó el blanco de las críticas que anunciaron la cristalización del cine argentino reprochando la ausencia de historias y la desidia de sus personajes. Por ejemplo, Juan Pablo Russo (2010) titula su crítica del film «Los tiempos muertos (o de cómo filmar la abulia)» en donde justamente expresa que «Ocio nos presenta más de lo mismo. Un cine en donde la abulia de los personajes se termina apoderando de la propia historia, haciendo que se termine por naufragar en un mar vacío de palabras y de bonitas imágenes». Asimismo, Miguel Frías (2010) describe la película de Ligenti y Villegas como un «film de atmósferas frías, distantes y abúlicas», resaltando la destreza formal y las actuaciones. Quiero destacar la expresión «bonitas imágenes» empleada por Russo al igual que la de Frías al referirse a la «destreza formal» del film, porque más allá de las críticas en cuanto a la reiteración de los personajes, corroboran la ubicación de este film dentro de la categoría de cine de la puesta en escena y situaciones mínimas. Son precisamente los diferentes espacios que habita el protagonista y su puesta en cuadro (la casa, su habitación y el barrio) los que adquieren pregnancia frente a la inacción de los personajes y la endeblez de la historia.

En Ocio el diálogo llega a su mínima expresión, al punto de ser prácticamente inexistente. La mayor manifestación verbal tiene lugar a través del monólogo y en boca de personajes eventuales: un amigo que le cuenta una historia a Andrés mientras miran televisión o un señor que le pide un cigarrillo en la plaza y arremete con reflexiones existenciales. Como señalé al comienzo, luego de enterrar a la madre de la familia, su esposo e hijos viven el duelo sin tener mucho para decirse. El silencio domina casi todas las escenas, con excepción de la aparición esporádica de música, especialmente rock nacional, ya sea de manera diegética o extradiegéticamente: en un segundo plano o para marcar una transición. Asimismo, las locaciones escogidas (un cementerio, un hospital y una iglesia) favorecen el silencio como materia expresiva y simbólica privilegiada. Como sostiene Agustín Campero, «el cine de Villegas es un ejemplo de la ideología central del nuevo cine, en cuanto a poner por delante el rigor de la puesta en escena y subordinar a ella todos los elementos narrativos y no narrativos que hacen a una película» (Campero, 2008, p. 68).

Con respecto a los personajes que pueblan las ficciones del corpus, ellos resultan ininteligibles, cualidad que impide que los podamos conocer y, mucho menos, comprender. Una característica que se reitera es su condición de seres anónimos: de ellos apenas sabemos su nombre, su edad, de qué viven o a qué se dedican. Simplemente, los protagonistas atraviesan situaciones rutinarias en las que se ven inmersos, sin experimentar conflictos ni variaciones de su estado de ánimo en el discurrir del filme. Se trata generalmente de personajes apáticos, carentes de entusiasmo, desarraigados y desencajados de su entorno, que no manifiestan ningún tipo de anhelo. Así como en toda película narrativa «(...) los personajes crean las causas y muestran los efectos. Dentro del sistema formal ellos hacen que las cosas sucedan y reaccionan a los giros de los eventos» (Bordwell, 2007, p. 63), los personajes que aquí examinamos se encuentran en las antípodas de dicha caracterización. Ellos suelen definirse por la pasividad, la quietud y la aparente no responsabilidad respecto de sus propias acciones. Las situaciones en las que se ven inmersos suelen darse por azar, siendo este el factor principal o la causa de su devenir en el relato, ya sea en los encuentros o desencuentros entre los personajes, ya sea en la determinación de sus destinos. Resulta inevitable, por la similitud de las descripciones, retomar el estudio sobre el cine de arte y ensayo de David Bordwell (1996). Por un lado, por el examen de la narración que efectúa consistente en escenas que se crean alrededor de encuentros fortuitos; y, por otro lado, y en relación con los personajes, porque estos no buscan nada y no tienen un objetivo que los movilice, simplemente transitan. Según el teórico los personajes están «faltos de trazos, motivos y objetivos claros» (1996, p. 207) y el protagonista se presenta deslizándose pasivamente de una situación a otra. 


\section{3) FILMS DE ESTRUCTURAS EPISÓdICAS QUE REMITEN A LA DIVISIÓN EN ACTOS}

DE LAS OBRAS TEATRALES. Dentro de esta categoría reconocemos a su vez dos variantes de la estructura episódica:

\section{A) FILMS CUYOS EPISODIOS SON ARGUMENTALMENTE INDEPENDIENTES ENTRE SÍ (A PROPÓSITO DE BUENOS AIRES, LUEGO, VIDRIOS).}

En estos films los episodios no se vinculan entre sí a través de una progresión narrativa y cada uno de ellos suele estar construido en distintos espacios y con diferentes personajes, más allá de abordar un tema en común (la exploración de la historia y la literatura, la soledad o la incomunicación y el desencuentro en las relaciones interpersonales).

En esta modalidad hay una separación definitiva entre actor y personaje o, para ser más exactos, el personaje llegó a su disolución total, en la medida que no tiene un nombre que lo identifique. Se trata, en todos estos casos, de la radical desaparición del personaje. En estos films cobra relevancia la presencia del actor en cuanto tal, por lo que el énfasis está colocado en ellos mismos (como portadores de una corporalidad y gestualidad determinadas y ejecutores que acciones físicas específicas) y en las diferentes situaciones ficcionales en las que intervienen, ya sea realizando acciones cotidianas y triviales, acciones verbales como la lectura y el recitado de textos literarios e históricos, ya sea explorando la escena como posibilidad de lograr diferentes estados emocionales. Según el «dogma imaginario» que formulaba irónicamente Segal (2007) respecto de las características del cine nacional al promediar la década del dos mil, entre las cuales se encontraban la actuación minimalista o la noactuación y la distancia de los personajes. Si bien planteado en un tono irónico, este dogma describe una forma de actuación equivalente a la que señalamos respecto del teatro. Se trata, en última instancia, del desvanecimiento del personaje y de la recuperación de la noción de actante en su acepción más básica, como aquel que realiza o lleva a cabo una acción determinada. Los actores dejan de representar un personaje para convertirse ellos mismos en pura presentación, por lo que, insistimos, su corporalidad y gestualidad se colocan en el centro de la poética actoral.

\section{A PROPÓSITO DE BUENOS AIRES}

A mediados de la década del dos mil surge una camada de jóvenes directores compuesta en su mayoría por egresados de la Fundación Universidad del Cine (FUC). La emergencia de este conjunto de jóvenes cineastas trajo consigo la aparición de un nuevo grupo de actores y actrices, la mayoría de ellos proveniente del ambiente teatral y, en algunos casos, incursionarán también en novelas televisivas. Tal es el caso de Esteban Lamothe, Esteban Bigliardi, Pilar Gamboa, Romina Paula, Julián Tello, Julia Martínez Rubio, María Villar, Ignacio Rogers o Julián Larquier Tellarini, jóvenes actores que se repiten una y otra vez en los films producidos en la segunda mitad de la década.

A propósito de Buenos Aires (2006, Manuel Ferrari, Alejo Franzetti, Martín Kalina, Cecilia Libster, Francisco Pedemonte, Clara Picasso, Matías Piñeiro, Juan Ronco, Andrea Santamaría, Malena Solarz y Nicolás Zukerfeld) es la carta de presentación de estos nóveles cineastas, un film colectivo gestado, realizado y producido por alumnos y ex alumnos de la Universidad del Cine. Así como ocurriera con Historias breves, se puede considerar a este film como una suerte de manifiesto fundacional en el que, antes de realizar sus propias películas individuales, los directores prefiguran los recorridos narrativos y expresivos que explorarán a continuación: la ciudad como escenario, los diálogos sin énfasis y la acciones débiles, la estructura fragmentaria que acoge en su interior una sucesión de cuadros que no 
siguen un estricto orden causal, el empleo de procedimientos realistas -planos de extensa duración y filmación en locaciones- combinados con otros que promueven un extrañamiento sistemático -digresión narrativa y nula presentación de los personajes y de los vínculos que mantienen entre sí- y, por último, la alusión al campo de la historia, la literatura, el teatro y el cine tanto nacional como universal. Los lugares de la ciudad que el film explora son la avenida Corrientes y la avenida Rivadavia, la Reserva Ecológica, el Teatro San Martín, la célebre confitería La Giralda, los lagos de Palermo, estaciones de trenes, el cementerio de la Recoleta y la Biblioteca Nacional. Por todos estos lugares los protagonistas transitan y construyen pequeñas y muy breves historias que no se configuran como tales, sino que muestran los hilos de algo latente que más adelante reaparece para volver a desvanecerse. $A$ propósito... edifica un entramado discursivo de referencias históricas y artísticas que se amalgaman con el presente transitado por los protagonistas, a partir de una superposición de lecturas de textos históricos y obras literarias (Roberto Arlt, Macedonio Fernández) que configura una relación dialógica entre el pasado y el presente. Los intertítulos que dividen el relato no separan o puntuar las múltiples escenas que conforman el film; su ubicación resulta completamente arbitraria y su función es la de organizar y dividir el conjunto de los fragmentos. Los protagonistas del comienzo que parecían haber quedado atrás resurgen para volver a desaparecer sin ninguna misión que la de la pura presencia.

A propósito de Buenos Aires resulta un claro exponente del cine posdrámatico o cine de situación, en tanto se trata de un «formato que, por su capacidad de acumulación, cierta inconexión entre sus partes y la versatilidad para admitir distintos géneros, se asemeja al género del pastiche (de voces en off, escenas actuadas, diálogos y paneos for export)» (Gorodischer, 2006). Estas propiedades formales de acumulación, discontinuidad, variabilidad y pastiche instituyen una morfología estructural que subyace a la serie cultural abordada en este artículo.

\section{LUEGO}

Realizado por Carola Gliksberg, este film se presentó en la octava Edición del BAFICI y participó de la Competencia Argentina. La concepción de las escenas, la escenografía, las entradas y salidas del campo visual y los diálogos de los personajes lo ubican dentro de la versión más radical del cine de situación.

A nivel temático, se narran tres historias breves con diferentes personajes: la primera corresponde a una pareja de amigos que se conocen desde la infancia -ella está enamorada de él pero no se atreve a decírselo-; la segunda transcurre en las horas previas de la despedida de una pareja; y la tercera se centra, por un lado, en la planificación de un viaje entre una madre y sus dos hijos con motivo de la graduación de uno de ellos, y por otro, en el ocultamiento de un secreto que nunca se termina de confesar. Las tres líneas argumentales se presentan sucesivamente y son construidas desde la puesta en escena con una evidente impronta teatral. Los encuadres son siempre centrados y fijos -exceptuando unos muy pocos y breves paneos de la cámara que sigue a los actores en sus mínimos desplazamientos-. Los personajes se ubican dentro del plano en una relación frontal y de cuerpo entero y más de una vez evidencian el dispositivo a través de la interpelación a la cámara.

Las tres historias están enmarcadas en espacios completamente despojados con fondos neutros y sus interiores están provistos únicamente por un solo elemento que sirve de referencia en la orientación espacial: una cama, un sillón, una mesa con dos sillas, un escritorio o una bañera. En el caso de que el plano esté desprovisto de todo elemento, los ruidos en off sugieren la ubicación de la acción (por ejemplo, los sonidos de la calle) o los mismos diálogos de los personajes permiten descifrar el 
sitio donde se encuentran. Es decir, en este film los espacios físicos que recorren los personajes se representan mediante el espacio acústico en off, desde la banda sonora en lugar de la banda de imagen.

Retóricamente las historias se construyen principalmente a partir de planos generales fijos, recortando espacios delineados por las entradas y salidas de campo de los personajes (desde los laterales). La mayoría de las escenas comienzan con el ingreso de un personaje al plano y finalizan luego de que se retiren, mostrando la porción visual vacía unos segundos antes de ser colmada por la acción y segundos posteriores de ser abandonada. Estas entradas y salidas crean el ritmo del film y le confieren un dinamismo que contrasta con el estatismo de los planos. En la actitud y el posicionamiento frontal y perpendicular de los actores en cada escena hay una conciencia corporal plena de la presencia de la cámara, conciencia que también se hace visible en la disposición dentro del cuadro de los elementos escenográficos: los amigos en el baño están parados uno al lado del otro, de cuerpo entero y en dirección al dispositivo o la pareja sentada en la mesa y comiendo se ubican también en la misma dirección. Esta frontalidad se invierte en la última historia, en cuyo plano inicial los tres personajes están sentados en un sillón de espaldas a la cámara.

Luego forma parte de la variante de films de estructura episódica cuyas secciones son argumentalmente independientes entre sí. Sin embargo, la singularidad que presenta es que el cruce de los personajes de las diferentes historias es el único contacto entre ellas, adquiriendo el sistema de entradas y salidas una función estructural. Cada historia se conecta con la siguiente mediante la superposición, en el último plano de cada trama, de los protagonistas. Estos, no tienen nombre y no son capaces de decir aquello que desean expresar. Los silencios, miradas, gestos y movimientos corporales hablan por aquello que callan. Hay algo que el cuerpo no puede contener pero que tampoco se puede pronunciar verbalmente. Gliksberg revela que es ese momento en el que alguien calla lo que tiene para decir, esa postergación constante de los personajes y sus discursos, lo que más le atrae trabajar en las tres historias (en Frías, 2008).

$\mathrm{Al}$ igual que en los otros filmes, aquí hay una voluntad expresa de priorizar la composición de la puesta en escena por encima de la historia. Así lo manifiesta la directora:

\begin{abstract}
Me interesa mucho más la puesta en escena que el tratamiento de un tema. Dejo que se note la construcción. Me manejo con deliberada artificialidad, sin llegar a lo godardiano, y con algunos recursos teatrales. Me gusta el cine de Ezequiel (Acuña). Pero mi director preferido es Fassbinder (en Frías, 2008).
\end{abstract}

\title{
VIDRIOS
}

Se trata de una producción independiente presentada en el BAFICI del 2013 y protagonizada por jóvenes provenientes del teatro y del cine nacional independiente, como Nahuel Viale, Ignacio Rogers, Julián Tello, Julia Martínez Rubio, Walter Jakob, Alberto Rojas Apel y Ailín Salas. En este film nos encontramos con diez escenas completamente autónomas e independientes entre sí que se suceden una tras otra sin ningún tipo de relación causal, aunque sí temática (la inestabilidad de los vínculos sociales). Todas ellas comparten el hecho de examinar las relaciones interpersonales desde diferentes ángulos como la ira, la incomunicación, la paranoia, el tiempo compartido, el aprendizaje y la solidaridad. Las diferentes situaciones que se suceden sin conexión se desarrollan en su mayoría en espacios cerrados (un bar, una habitación, una cocina, un ascensor) y los vínculos abordados son principalmen- 
te de amistad y de pareja. Este film es un exponente más de lo que denominamos cine de situación dado que los diversos episodios presentan esbozos de conflictos que no terminan de desarrollarse y mucho menos de resolverse, ya sea que se trate de conflictos internos, de relación con otros personajes o externos (un ascensor que se detiene en la mitad de la noche o un corte de luz). Cada una de las secuencias pone a prueba a sus protagonistas, quienes se enfrentan a problemas de diversa índole mostrando la fragilidad de la psiquis y de las relaciones humanas. Asimismo, se aborda la ausencia de conflicto en su forma extrema: un episodio está conformado por un extenso plano secuencia con dos chicos sentados en el piso y en penumbras, sin decir palabra, con la cámara fija y a la altura del suelo.

$\mathrm{Al}$ igual que sucedía en Luego, en Vidrios los personajes son entes anónimos sin más características que lo que muestran en ese aquí y ahora que dura la escena: nerviosos, paranoicos, pensativos, irascibles y reflexivos. Sobre la incapacidad de decir, Ignacio Bollini y Federico Luis Tachella aseguran que «los personajes de Vidrios nunca pueden decir lo que realmente sienten» (en Russo, 2013) porque los conflictos están por fuera de las situaciones que se muestran, al tiempo que las intenciones de los personajes por arribar a diálogos sinceros desembocan siempre en el absurdo.

\section{B) FILMS CUYOS EPISODIOS ESTÁN CONECTADOS POR LOS MISMOS PERSONA-} JES Y POR UNA MISMA TRAMA (CASTRO, TODOS MIENTEN, EL TURNO NOCTURNO). Si bien en este tipo de films los episodios están articulados por medio de la historia y de los mismos personajes, la relación causa-efecto de las acciones es endeble y el comportamiento de los protagonistas impredecible.

\section{CASTRO}

Este film constituye el primer largometraje de Alejo Moguillansky ${ }^{6}$, se rodó en quince días y es considerada la película hermana de Todos mienten de Matías Piñeiro, en tanto las dos se filmaron entre diciembre de 2008 y enero de 2009, son de la misma productora (Pampero Cine) y compartieron equipos y actores. Juntas tuvieron su primera presentación en el Buenos Aires Festival Internacional de Cine Independiente (BAFICI) en abril del 2009 y fue Castro la ganadora a la mejor película de la competencia argentina. También se estrenaron juntas en el Museo de Arte Latinoamericano de Buenos Aires (MALBA), lugar de exhibición alternativo al circuito comercial para determinadas producciones del cine argentino de los últimos años.

A nivel retórico, el film se organiza en once episodios divididos por intertítulos. Estos describen la acción que tiene lugar a continuación, el nombre del personaje sobre el cual se centrará la narración o reiteran una frase mencionada por uno de los personajes. Desde el comienzo del film y a lo largo de cada uno de los episodios, el motor de la narración es la búsqueda desenfrenada de Castro, personaje cuyo nombre da título al film, es el eje articulador de los diversos episodios y asegura el vínculo de los demás personajes: todos ellos quieren una misma cosa (encontrar a Castro) pero nunca sabremos por qué. Se trata, en palabras de Moguillansky, de un «registro delirante de sonámbulos corriendo a toda velocidad por la ciudad» ${ }^{7}$. El film se aventura en la novedad formal permanente y en la revalorización del plano, en un intento consciente, planificado y explicitado por Moguillansky de «empujar al cine

\footnotetext{
${ }^{6}$ Antes realizó cortos y mediometrajes como La prisionera (2006) y Borges/Santiago, variaciones sobre un guión (2008).

${ }^{7}$ Extraído de: http://www.malba.org.ar/web/cine pelicula.php?id=3443\&idciclo $=632 \&$ subseccion $=$ programacion pasada.
} 
hacia lugares en los que todavía no es». A partir de una excusa narrativa básica o esqueleto argumental (una persecución), el director desarrolla resuelta y coreográficamente la exploración de diversos espacios urbanos como fundadores de una ficción que se edifica entre registros opuestos, pero evidentemente complementarios y subsidiarios uno de otro: una observación realista a partir de recursos como los planos secuencias y travellings en exteriores, pero de situaciones estrambóticas la mayoría de las veces.

Ubicamos a Castro también dentro del cine de situación porque se construye a partir de la puesta en situación de unos personajes y su devenir en el interior de una trama, la cual constituye un vehículo para la exploración de la forma y de lo que acontece frente a la cámara ${ }^{8}$.

\section{TODOS MIENTEN}

La historia se centra en un grupo de amigos que pasan unos días en una casa quinta en las afueras de Buenos Aires. En una aparente quietud, los personajes se sumergen en varias subtramas que no guardan relación entre sí pero que van conformando ese mundo apacible y lúdico que propone Matías Piñeiro, con citas históricas, literarias y cinéfilas. El film se construye episódicamente, con intertítulos que funcionan de separadores entre una escena y otra. En cada una de ellas, los personajes realizan diferentes actividades como leer, hacer jardinería, cantar, andar en bicicleta, pintar o simplemente dormir. No hay un conflicto que dé sentido a la sucesión de los episodios, sino que asistimos al discurrir de los personajes y a las relaciones que se tejen entre ellos en un tiempo de ocio y lejos de su cotidianeidad. En ese lapso de distensión se deja entrever el presunto plan de Helena de abandonar la casa luego de escribir una historia sobre JMR y los integrantes de la vivienda. El artilugio de la protagonista ofrece pistas para pensar que el mismo film es esa historia que escribe, confiriendo a la estructura narrativa la percepción de una puesta en abismo.

Piñeiro postula un universo nuevo a partir de lo lúdico y de la mentira, «jugar con el acto de mentir como posibilidad de invención de un nuevo orden de cosas que pueda por caminos extraños acercarse a cierta verdad. Mentir como un proceso positivo de producción de mundos» (Piñeiro, 2009). No sabemos nada de ninguno de los personajes, solo conocemos lo que fingen y deciden mostrar a los demás, ya sea por fuera del grupo o entre ellos mismos. Por ejemplo, Helena (Romina Paula) parece ser la tataranieta de Sarmiento, Emilia (Pilar Gamboa) se hace pasar por una crítica y galerista de arte española para engañar a JMR (Esteban Lamothe), Mónica (María Villar) finge atravesar un estado de shock, Isabel (Julia Martínez Rubio) pinta cuadros que firma haciéndose pasar por su ex novio, JMR e Iván (Esteban Bigliardi) repite insistentemente que se va y no lo hace.

La cámara muchas veces no se detiene a registrar visualmente los diálogos de los personajes, sino que estos quedan en un plano acústico en off, eligiendo mostrar lo que ocurre al fondo de la escena o en otro espacio y adquiriendo de esa forma la autonomía respecto de los personajes y sus acciones. Dicha autonomía convierte por momentos a la cámara en un personaje más dentro del grupo de amigos: en algunas escenas sigue a un personaje y luego lo abandona para observar una escena que está sucediendo en un espacio contiguo, si bien seguimos escuchando a ese mismo personaje en off; otras veces observa de lejos al grupo de amigos practicando alguna actividad al aire libre; también deambula por la casa al igual que los personajes que entran y salen de los cuartos (incluso de los armarios) y se

\footnotetext{
${ }^{8}$ En relación con el teatro posdramático, en otra oportunidad examiné el diálogo que este film establece con la obra teatral La escala bumana (2001) de Alejandro Tantanián, Javier Daulte y Rafael Spregelburd (Soria, 2015a). En ambas textualidades puede reconocerse la estética absurdista como estructura subyacente y la trasgresión sistemática a las reglas del género policial, mediante estructuras fragmentarias en las que los acontecimientos dramáticos se organizan de un modo no lineal y disruptivo.
}

Ediciones Universidad de Salamanca / CC BY - NC ND $\quad$ Fonseca, Journal of Communication, n. 15, 2017, pp. 163-184 
inmiscuye en las rondas grupales con insistentes primeros planos de los protagonistas. En uno de los episodios, por ejemplo, una cámara fija observa desde el interior de un cuarto que se supone vacío el exterior, espiando a dos de los protagonistas que no hacen otra cosa que pasar el tiempo al aire libre. De la misma manera que ocurría en Castro con los desplazamientos coreografiados de los personajes por las dos ciudades, aquí los personajes van y vienen por el espacio acotado de la quinta, en un movimiento y circulación permanente: entradas y salidas de habitaciones, puertas que se abren y cierran.

Tanto en Castro como en Todos mienten apenas sabemos quiénes son los personajes, qué persiguen y por qué lo hacen (el film de Moguillansky es el ejemplo más paradigmático de la indeterminación, en tanto asistimos a una persecución durante todo el film sin llegar a saber nunca por qué lo persiguen a Castro). Hay una especie de intersticio entre lo que se quiere expresar verbalmente, pero las palabras no pueden nombrar. En todos los casos se trata de personajes que construyen su identidad desde la exterioridad. Por un lado, desde lo corporal (la gestualidad y expresividad del rostro, sus movimientos, su modo de estar en la escena); y por otro, desde el discurso.

\section{EL TURNO NOCTURNO}

La ópera prima de Matías Rispau se presentó en el Festival Buenos Aires Rojo Sangre (BARS) -Festival internacional de cine de terror, fantástico y bizarro- y obtuvo el premio a Mejor Película Panorama Nacional por VideoFilms en el 2011. A nivel temático, este film recorre las horas de trabajo de Diego en el turno nocturno de una estación de servicio. Su amigo Javier vive frente a la estación y lo acompaña en su jornada laboral, ya que no trabaja porque está esperando «que una ráfaga de viento lo inspire a estudiar algo». A medida que avanza la noche, desfilan por el lugar de trabajo personajes insólitos y se suceden situaciones de lo más extrañas. Entre los personajes que circulan se encuentran el Señor Siniestro, la Mujer histérica, el Hombre niño, el Capitán Fulano, el «Breakdancer», el Secuestrador, el Mariachi líder y el Maricahi suicida. Todos ellos se presentan en el prólogo y aparecen a medida que progresa la narración organizada de forma episódica. Cada uno de los episodios (en total once) es antecedido por el horario en que tiene lugar la escena que vendrá a continuación y por un título que refiere vagamente a la situación. ¿Por qué analizamos este film como una variante más de un cine de situación? ¿A partir de qué procedimientos podemos encontrar puntos de contacto con el teatro de la década anterior? Por un lado, por la estructura fragmentaria en que es contada la historia. Por otro, por la historia misma, plagada de situaciones descabelladas que lindan constantemente con el inverosímil y lo incierto. Asimismo, El turno nocturno tiene una impronta teatral clásica en lo que respecta a la unidad de tiempo (el transcurso de una noche), de espacio (la estación de servicio) y de acción (el desenvolvimiento del empleado ante diversas circunstancias que no son necesariamente laborales). Si bien este film tiene un fuerte anclaje realista en cuanto a su ambientación (la estación) y el modo de registrarla con numerosos planos secuencia y la cámara en movimiento, el absurdo toma la posta en cada una de las situaciones en las que se ve involucrado Diego, además de ser subrayado por medio de la música. Esta última remite a géneros como el cine de aventuras y de suspense y crea los diferentes climas narrativos que se suceden sin una estricta causalidad. La linealidad la otorga únicamente y como ya dijimos, la hora que inaugura cada secuencia. 


\section{CONSIDERACIONES FINALES}

De lo expuesto hasta aquí y tras los análisis efectuados de los films que conforman el corpus de este artículo, es posible identificar una textualidad fímica que tiene como denominador común aquellos elementos que caracterizan lo que propuse denominar cine de situación: primacía de la composición de la imagen por encima de la historia y digresión narrativa. Al adentrarnos en las singularidades de cada relato reconocimos una indudable impronta teatral que, tras examinar en detalle cada caso específico, pudo organizarse en las diferentes formas de asimilación del teatro en el cine, eje vertebrador de este trabajo y que permite seguir reflexionando sobre la cinematografía argentina contemporánea.

Los aspectos formales examinados -como los procedimientos narrativos y expresivos, la construcción temporal y espacial, el sistema de personajes y la poética actoral-acreditan una matriz común de los films y sus especificidades permiten organizarlos en las diferentes modalidades de asimilación esbozadas. Por otro lado y a nivel temático, es posible reconocer que el corpus despliega una variedad de matices sobre tópicos existenciales que dirigen la mirada a cuestiones referidas principalmente a la condición humana y su modo de estar y atravesar el mundo: la búsqueda de sentido, los vínculos circunstanciales y el tedio en Sábado, en Incómodos y en Ocio; la incomunicación y la privacidad desplazada en Todo juntos; el paso del tiempo y el refugio en lo introspectivo ante la extrañeza del presente en Extraño; la melancolía y la construcción de nuevos lazos solidarios en Cuatro mujeres descalzas; la construcción de diferentes formas de relaciones interpersonales en Luego y en Vidrios; el sin sentido de la existencia, la futilidad del trabajo y el absurdo en Castro y El turno nocturno; y el tándem aparienciaverdad a través de lo lúdico en Todos mienten. Se trata de tópicos que encuentran en las narraciones disruptivas y en las estructuras fragmentarias un canal adecuado de expresión.

Por último, el objetivo final de este trabajo es que las modalidades propuestas continuen expandiéndose y creando nuevas formas de análisis y abordajes, en un movimiento incesante como aquel que generan las ondas.

\section{BIBLIOGRAFÍA}

Aguilar, G. (2010). Otros mundos. Un ensayo sobre el nuevo cine argentino. Buenos Aires: Santiago Arcos Editor.

Aguilar, G. (2007). El escenario de lo real (el nuevo cine argentino y el teatro). Cuadernos del Picadero, $14,19-21$

Aumont, J. (2013). El cine y la puesta en escena. Buenos Aires: Colihue Imagen.

Bernini E., Choi, D. y Goggi, D. (2003). Los no realistas. Conversación con Ezequiel Acuña, Diego Lerman y Juan Villegas. Kilómetro 111. Ensayos sobre cine, 5.

Bauman, Z. (2002). Modernidad líquida. Buenos Aires: FCE.

Bettetini, G. (1984). Tiempo de la expresión cinematográfica. México: FCE.

Blejman, M. (2003). Vidas privadas en espacios públicos. Página 12. Recuperado de: https://www.pagina12.com.ar/diario/espectaculos/6-26446-2003-10-08.html

Bordwell, D. (1996). La narración en el cine de ficción. Barcelona: Paidós.

Bordwell, D. y Thompson K. (2007). Arte Cinematográfico. México: Mc Graw Hill.

Campero, A. (2008). Nuevo Cine Argentino. De Rapado a Historias extraordinarias, «Colección 25 años, 25

libros». Buenos Aires: Universidad Nacional de General Sarmiento, Biblioteca Nacional.

Filippelli, R. (2001). El último representante de la Nouvelle Vague. Revista El amante, 10(115), 6-8.

Fontana, J. C. (2005). La actuación, o como ser uno mismo en el escenario. Revista Picadero, 4(14), $10-$ 12.

Ediciones Universidad de Salamanca / CC BY - NC ND $\quad$ Fonseca, Journal of Communication, n. 15, 2017, pp. 163-184 
Frías, M. (2010). Final de época. Clarin.com. Recuperado de:

https://www.clarin.com/extrashow/cine/Final-epoca 0 BkJlAY5pvQl.html

Frías, M. (2008). Entrevista a Carola Gliksberg: 'Me interesan los antihéroes'. Clarin.com. Recuperado de: https://www.clarin.com/extrashow/interesan-antiheroes 0 rybgKFaAatx.html

García, L. (2003). Entrevista a Federico León: 'Esta película es mi diario íntimo', en La Nación. Recuperado de: http://www.lanacion.com.ar/533801-leon-esta-pelicula-es-mi-diario-intimo

Gorodischer, J. (2006). Once directores detrás de la cámara. Página 12. Recuperado de: https://www.pagina12.com.ar/diario/suplementos/espectaculos/5-2355-2006-04-21.html

Jacobs, D. (2007). Merecer las imágenes. Cuadernos de Picadero, 14, 34-41.

Lehmann, H.-Th. (2012). El teatro no es político por su contenido, sino porque está hecho de un modo político (entrevista realizada por Ivanna Soto). Revista N.

Lehmann, H.-Th. (2010). El teatro posdramático, una introducción. Telóndefondo. Revista de teoría y crítica teatral, 12.

León, F. (2005). Registros: teatro reunido y otros textos. Buenos Aires: Adriana Hidalgo Editora.

Loza, S. (2014). Textos reunidos. Buenos Aires: Biblos.

Mauro, K. (2015). Acción actoral y situación de actuación en cine. Imagofagia. Revista de la Asociación Argentina de Estudios de Cine y Audiovisual, 11.

Mauro, K. (2015). (2013). La Actuación en el Teatro Posdramático argentino. Revista Brasileira de Estudos da Presença, 3, 669-692.

Maxwell, R (2013). Federico León en Español. BOMB, Artists in Conversation. Recuperado de: http://bombmagazine.org/article/7129/federico-le-n-en-espa-ol

Nichols, B. (2007). El documental y el giro de la vanguardia. Archivos de la Filmoteca, 56, 16-45.

Pérez Bowie, J. A. (2004). Teatro y cine: un permanente diálogo intermedial. Arbor, 177(699-700), $573-$ 594.

Piñeiro, M. (2009). Notas del director. El Bazar del Espectáculo. Recuperado de: http://elbazardelespectaculocine.blogspot.com.ar/2009/09/castro-todos-mienten-sinopsisficha.html\#.WWkFZtM1-34

Russo, J. P. (2013). Entrevista a Ignacio Bollini y Federico Luis Tachella: 'Los personajes de Vidrios nunca pueden decir lo que realmente sienten'. Escribiendocine.com. Recuperado de: http://www.escribiendocine.com/entrevista/0007677-ignacio-bollini-y-federico-luis-tachella-lospersonajes-de-vidrios-nunca-pueden-decir-lo-que-realmente-sienten/

Russo, J. P. (2013). (2010). Los tiempos muertos (o de cómo filmar la abulia). Escribiendocine.com. Recuperado de: http://www.escribiendocine.com/critica/0000746-los-tiempos-muertos-o-de-comofilmar-la-abulia/

Guido S. (2007). Propuestas para un verdadero Nuevo Cine en cuatro tiempos. El Amante, 181, 6-7.

Soria, C. (2015a). El absurdo y la transgresión al policial en el teatro y el cine argentino contemporáneo: análisis de un diálogo intermedial. European Review of Artistic Studies. 6(3), 18-29.

Soria, C. (2015b). Sistematizar el caos: reglas cardinales comunes al teatro y al cine argentino contemporáneo. Telondefondo. Revista de Teoría y Crítica Teatral, 11(22), 44-52. Recuperado de: http://revistascientificas. filo.uba.ar/index.php/telondefondo/article/view/2155 


\section{LISTADO DE FILMS MENCIONADOS}

A propósito de Buenos Aires (AA. VV., 2006)

Castro (Alejo Moguillansky, 2009)

Cuatro mujeres descalzas (Santiago Loza, 2004)

El turno nocturno (Matías Rispau, 2011)

Extraño (Santiago Loza, 2003)

Incómodos (Esteban Menis, 2008)

La invención de la carne (Santiago Loza, 2009)

Luego (Carola Gliksberg, 2008)

Ocio (Alejandro Lingenti y Juan Villegas, 2010)

Sábado (Juan Villegas, 2001)

Todo juntos (Federico León, 2002)

Todos mienten (Matías Piñeiro, 2009)

Vidrios (2013, Ignacio Bollini y Federico Luis Tachella, 2013)

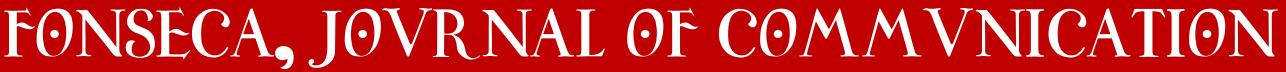

